\title{
Effect of nanofillers on the dielectric properties of epoxy nanocomposites
}

\author{
Q. Wang* and G. Chen \\ School of Electronics and Computer Science, University of Southampton, Southampton, United Kingdom
}

(Received August 31, 2011, Revised March 19, 2012, Accepted March 20, 2012)

\begin{abstract}
Epoxy resin is widely used in high voltage apparatus as insulation. Fillers are often added to epoxy resin to enhance its mechanical, thermal and chemical properties. The addition of fillers can deteriorate electrical performance. With the new development in nanotechnology, it has been widely anticipated that the combination of nanoparticles with traditional resin systems may create nanocomposite materials with enhanced electrical, thermal and mechanical properties. In the present paper we have carried out a comparative study on dielectric properties, space charge and dielectric breakdown behavior of epoxy resin/nanocomposites with nano-fillers of $\mathrm{SiO}_{2}$ and $\mathrm{Al}_{2} \mathrm{O}_{3}$. The epoxy resin (LY556), commonly used in power apparatus was used to investigate the dielectric behavior of epoxy resin/nanocomposites with different filler concentrations. The epoxy resin/nanocomposite thin film samples were prepared and tests were carried out to measure their dielectric permittivity and tan delta value in a frequency range of $1 \mathrm{~Hz}-1 \mathrm{MHz}$. The space charge behaviors were also observed by using the pulse electroacoustic (PEA) technique. In addition, traditional epoxy resin/microcomposites were also prepared and tested and the test results were compared with those obtained from epoxy resin/nanocomposites.
\end{abstract}

Keywords: nanocomposites; epoxy resin; nanofillers; dielectric properties; space charg; dielectric strength

\section{Introduction}

Epoxy resin is one of the most commonly used thermosetting materials in high voltage apparatus as insulation due to its excellent mechanical, electrical properties and chemical stability. In recent years, the nano reinforced epoxy resin has attracted a wide interest as it enhances the epoxy's properties significantly (Fothergill et al. 2004, Lewis 2004, Nelson and Hu 2004). Researches on nano reinforced epoxy resin composites have been carried out ceaselessly. The recent investigation has shown that the epoxy/nanocomposites demonstrate some advantages in both mechanical and dielectric properties (Singha and Thomas 2008a, Tanaka 2005) compared with pure resin system and epoxy with micrometer-size fillers at a lower loading concentration (1-10 wt \%). One of the interesting observations was that over a wide range of frequencies, the dielectric permittivity values in epoxy nanocomposites are normally lower than both base resin and epoxy with micrometer-size fillers at lower concentrations (depend on filler type and size) (Ciuprina et al. 2008, Singha and Thomas 2008c, Tanaka 2005). For both $\mathrm{TiO}_{2}$ and $\mathrm{ZnO}$ nano fillers, as the loading filler concentration

*Corresponding author, Ph.D. Candidate, E-mail: qw08r@ecs.soton.ac.kr 
increases, the permittivity of epoxy nanocomposites increases as well (Singha and Thomas 2008a). Earlier researches also showed that the presence of nano fillers in epoxy resin affects the space charges accumulation in epoxy resin (Castellon et al. 2010, Fabiani et al. 2008, Green 2008). It is well known that the presence of space charge has a huge influence on dielectric properties of insulation polymer. Earlier research showed that the accumulation of space charge can affect the internal electric field, which may lead to a breakdown of the insulating polymer (Dissado et al. 1997, Zheng et al. 2005). The presence of space charge has become a problem for insulation material application. Therefore, it is important to study how to avoid space charge accumulation or reduce its influence on dielectric behavior of insulation materials. The recent investigation has shown that epoxy nanocomposites seem to accumulate less charge compared with filler-free epoxy resin (Castellon et al. 2008). It was also observed that epoxy nanocomposites have faster charge dynamics, especially for negative charges (Fabiani et al. 2008).

The purpose of the present paper is to study the effects of nano-size fillers on space charge behaviors, dielectric permittivity and breakdown behaviors of epoxy/nanocomposites. It aims to investigate the effects of the filler type and concentration on epoxy/nanocomposites' dielectric properties. Both $\mathrm{SiO}_{2}$ and $\mathrm{Al}_{2} \mathrm{O}_{3}$ nano fillers are used in this study. The permittivity of epoxy/ nanocomposites with different concentrations is measured, the pulsed electroacoustic technique is used to monitor space charge behaviors of the samples and the breakdown behaviors of epoxy/ nanocomposites with different concentrations have been measured.

\section{Experimental details}

\subsection{Materials}

The materials used in this study to produce epoxy resin specimen were Araldite LY556 (Bisphenol-A type) and the hardener HY917 (anhydride type hardener), supplied by Huntsman. The epoxy resin system is widely used in practice and has an advantage of low viscosity at room temperature. Both nanoparticles of silicon dioxide (average diameter $25 \mathrm{~nm}$ ) and aluminum oxide (diameter 30-40 nm) supplied by NanoAmor were used as fillers. Micro-sized $\mathrm{SiO}_{2}$ fillers supplied by Huntsman were also used to show the influence of filler size on the dielectric properties of epoxy resin.

\subsection{Sample preparation process}

The mould used to produce epoxy/nanocomposites consists of two metal plates, with a polymer film spacer in the middle. The thickness of epoxy specimens is controlled by the thickness of the spacer. For this study the thickness of spacer used is $200 \mu \mathrm{m}$. The plate surface was polished to achieve even and smooth sample surfaces. To help release the specimen from the mould after curing, both the plate surfaces were smeared with a very thin layer of silicon grease.

The suggested mix ratio of araldite and hardener 1:0.9 (by weight), and the concentration of accelerator is 1 parts in per 100 parts epoxy resin. The epoxy resin specimens $(200 \mu \mathrm{m})$ with loading concentrations of nano-fillers (both $\mathrm{SiO}_{2}$ and $\mathrm{Al}_{2} \mathrm{O}_{3}$ ) $0.1 \mathrm{wt} \%, 0.3 \mathrm{wt} \%, 0.5 \mathrm{wt} \%, 1 \mathrm{wt} \%$, $3 \mathrm{wt} \%$ and $5 \mathrm{wt} \%$ were produced. Pure epoxy resin specimens and specimens with micro-size $\mathrm{SiO}_{2}$ fillers were also prepared for comparison purpose. Before the process of preparing epoxy resin 


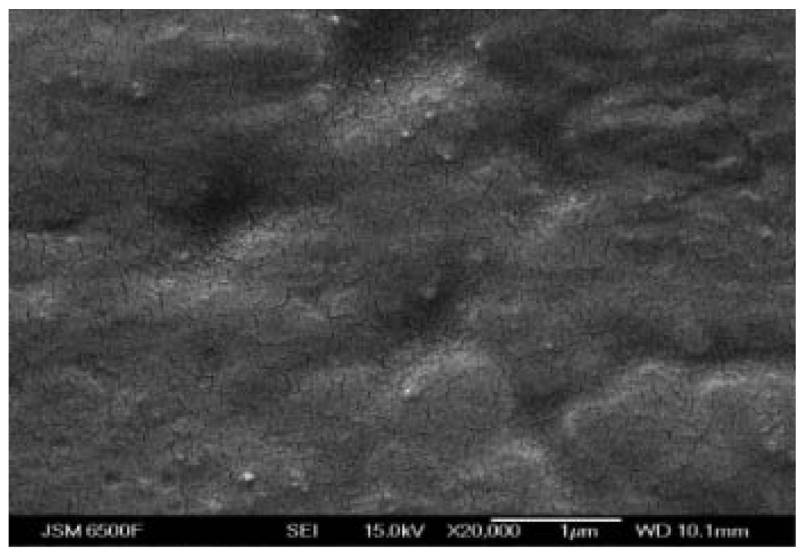

Fig. 1 SEM Image of the Epoxy- $\mathrm{SiO}_{2}$ Nanocomposite

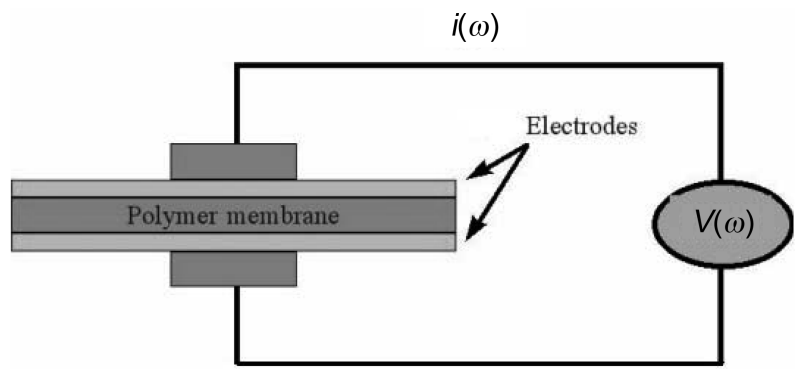

Fig. 2 Sample test cells for dielectric spectroscopy measurement

specimen, epoxide needs to be pre-heated to $40^{\circ} \mathrm{C}$ in an oven to reduce its viscosity. Then both epoxy resin and hardener were poured into beakers separately. To remove the gas bubbles, both of them need to be degassed in a vacuum oven for $1 \mathrm{~h}$ at $40^{\circ} \mathrm{C}$ before mixing. After the completion of the degassing process, the fillers (micro and nano) were dispersed into epoxy resin slowly with hand stirring. The hardener was added into the resulting epoxy/nano-filler solutions and then the mixture was stirred with both a high speed mechanical mixer (at $600 \mathrm{rpm}$ ) and an ultrasonic liquid processor for $1 \mathrm{~h}$ each. The mixture was degassed in the vacuum oven for another $20 \mathrm{~min}$ at $40^{\circ} \mathrm{C}$ to remove any gas bubbles generated during the mixing process. After degassing, the mixture was poured into the mould. Then the mould was placed into the oven at $80^{\circ} \mathrm{C}$ to cure for $4 \mathrm{~h}$ followed by $4 \mathrm{~h}$ postcure at $120^{\circ} \mathrm{C}$. Finally removing the cured resin from the mould, the $200 \mu \mathrm{m}$ specimen was ready for testing.

Scanning electron microscope (SEM) was used to exam the dispersion of the nano-size filler in the epoxy/nanocomposites. The even dispersion of the nano-size filler in the resin can be seen from Fig. 1. Therefore it can be confirmed that the filler dispersed uniformly in the specimens.

\subsection{Dielectric spectroscopy measurements}

The dielectric permittivity of epoxy/nanocomposites was measured over a wide range of frequencies using dielectric spectroscopy (Solatron 1260). The dielectric spectroscopy is based upon 


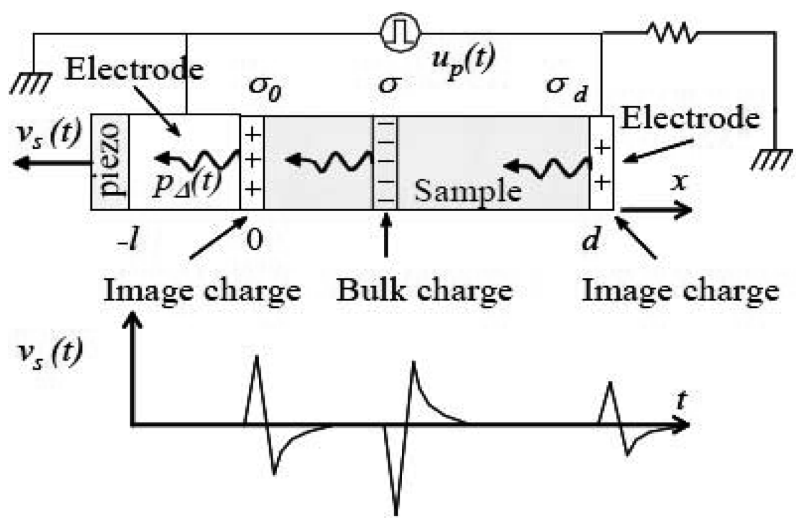

Fig. 3 Principle of PEA method

the interaction of the electric dipole moments within the sample and the applied filed, and provide the dielectric properties of materials, such as relative permittivity and loss factor. By testing the sample's dielectric properties, the information about mobility of polymers can be provided. Thus researches on dielectric spectroscopy measurement have been carried out ceaselessly. A sample test cell for dielectric spectroscopy measurement is shown in Fig. 2.

During the test, both the magnitude and tan delta value of the epoxy resin composites' dielectric permittivity over a range of $0.1 \mathrm{HZ}$ to $1 \mathrm{MHZ}$ were measured. The sample was cut into a circle with $25 \mathrm{~mm}$ in diameter and the thickness of the sample was $200 \mu \mathrm{m}$. The applied voltage was set to $1 \mathrm{~V}$ and the resulting relative permittivity and its loss characteristics ( $\tan \delta$ value) were measured. During all the measurements, room temperature was maintained.

\subsection{Space charge measurements}

PEA is used to measure the space charge distribution and displacement in the samples. The idea of PEA measurement is to apply a short pulse voltage across the sample and therefore observe its charge distribution. Its basic principle is given in Fig. 3.

In PEA measurements, the dielectric samples are placed between two electrodes. Because of the difference in the acoustic impedance between the electrode and samples, silicone oil is spread on the surface of both electrodes before the experiments to avoid forming acoustical interface between the electrode and samples. Then a short pulse voltage $u p(t)$ from one of the electrodes is applied to the sample to produce an electric field impulse. The pulse voltage will cause the space charge inside the sample (if there is any) to experience a pulse force which travels between the two electrodes and therefore results in a displacement under the Coulomb force as Eq. (1).

$$
\vec{F}=q \vec{E}
$$

Therefore the acoustic wave with amplitude proportional to the local charge density inside the sample will be able to be detected by a piezoelectric sensor which is positioned under the other electrode. Then the piezoelectric sensor will transform the acoustic wave into electric signals. The signal will be transferred and recorded in an oscilloscope as a function of time. Fig. 4 shows the schematic diagram of PEA system for film sample. 


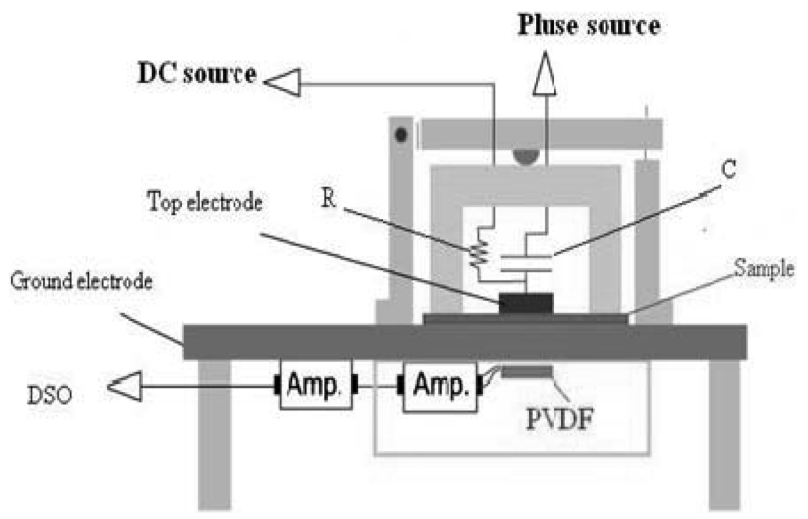

Fig. 4 Pulsed electro-acoustic (PEA) system for film sample

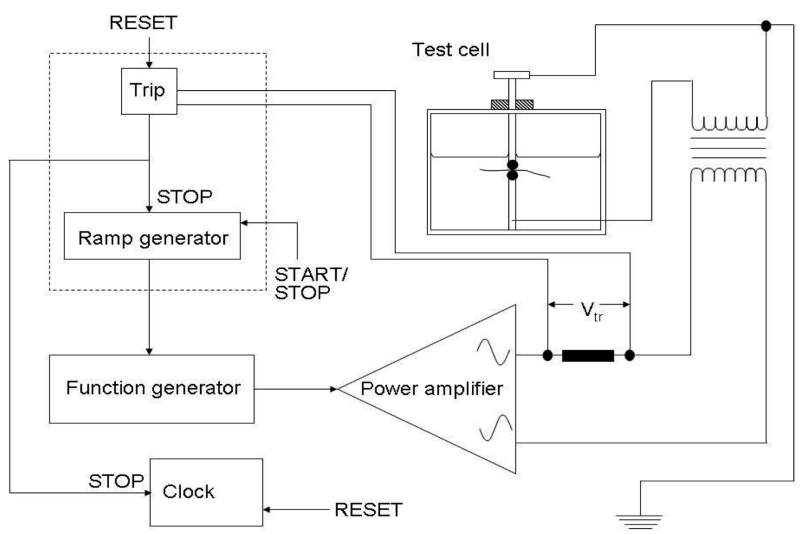

Fig. 5 Schematic diagram of AC dielectric breakdown kit

During the test, a voltage of $6 \mathrm{kV}$ had been applied to specimens with approximately $200 \mu \mathrm{m}$ thickness (The applied field is $30 \mathrm{kv} / \mathrm{mm}$ ) at room temperature (approximately $20^{\circ} \mathrm{C}$ ) for 90 minutes. In the present case, the results from "volts-off" measurements were used to investigate the charge accumulation in the specimens. The "volt-off" measurement measures charge formation immediately after the applied voltage has been removed.

\subsection{Dielectric breakdown measurements}

The AC dielectric breakdown behaviors were measured by using a purpose-built kit based on ASTM standard D149-87 (Dissado and Fothergill 1992, Green 2008). The schematic diagram of this kit is shown in Fig. 5. The sample is immersed in Dow Corning 200/20 cs silicone fluid, between two $6.3 \mathrm{~mm}$ steel ball bearings. The upper electrode, which the upper ball bearing is attached to, has a $50 \mathrm{~g}$ load added, to both ensure the sample is sufficiently held in position and also, to eliminate a film of oil between the electrode and the sample, which could potentially interfere with results. The breakdown kits used in this project is also shown in Fig. 21. The ramp testing method has been used to test the breakdown strength of epoxy samples. The process is simply applying a linearly 


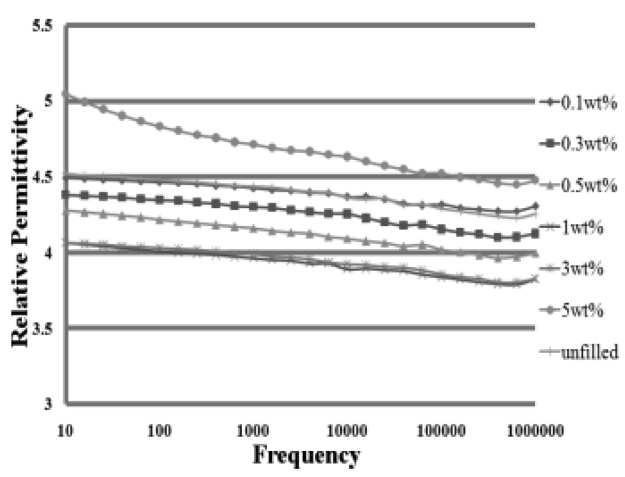

(a) Epoxy- $\mathrm{SiO}_{2}$ nanocomposites

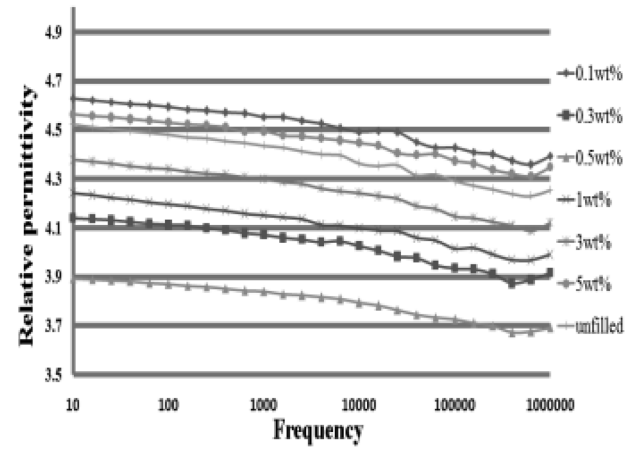

(b) Epoxy- $\mathrm{Al}_{2} \mathrm{O}_{3}$ nanocomposites

Fig. 6 Variations of permittivity with respect to frequency

increased voltage to the tested sample, until the breakdown occurs. With this purpose-built kit, both the breakdown voltage, $V b d$, and time taken for breakdown to happen can be recorded down. Thus the breakdown strength, $E$, of the epoxy resin film can be worked out with Eq. (2)

$$
E=V b d / d
$$

where, $d$ is the sample thickness. During testing, a $50 \mathrm{~Hz}$ voltage is ramped from 0 to $18 \mathrm{kV}$ at a rate of $50 \mathrm{~V} / \mathrm{s}$. The high voltage is measured using a 10000:1 potential divider and a Precision Gold WG 020 digital multi-meter.

The Weibull 7++ software package (Supplied by Reliasoft) has been used to analysis the results. The Weibull distribution is a continuous probability distribution that is used to describe breakdown distribution, first introduced by Weibull in 1951. It is the most commonly used probability distribution in breakdown studies due to its flexibility. It is also the IEEE recommends standard probability distribution. The Weibull distribution allows either one, two or three parameters being used to describe the breakdown distribution. In this project, a two parameter Weibull is selected to analyse the breakdown results due to its best overall performance. The equation of a two parameter Weibull is shown as Eq. (3)

$$
P_{f}(x)=1-\exp \left[-\frac{\left(x-x_{t}\right)}{\alpha}\right]^{\beta}
$$

where $P_{f}(x)$ is the cumulative probability of failure at time $x, x_{t}$ is a threshold time, which means that before time $x_{t}$, no failures can occur. Both $\alpha$ and $\beta$ are known as location and shape parameters respectively.

\section{Results and discussion}

\subsection{Permittivity and tan}

The variations of dielectric permittivity as a function of frequency for both epoxy/nanocomposites with $\mathrm{SiO}_{2}$ and $\mathrm{Al}_{2} \mathrm{O}_{3}$ nano fillers and with different concentrations are shown in Fig. 6. The results 
show that for all epoxy/nanocomposites loading with $\mathrm{SiO}_{2}$ and $\mathrm{Al}_{2} \mathrm{O}_{3}$ nano fillers and with different concentrations, there is a clear reduction in effective permittivity within the measured frequency range. It is known that the effective permittivity of the epoxy/nanocomposites is found to be governed by the polarization associated with epoxy and nano $\mathrm{SiO}_{2} / \mathrm{Al}_{2} \mathrm{O}_{3}$ particles and it is also being strongly influenced by the interfacial polarization at the interface between epoxy and nano particles as well. Therefore, such a reduction in effective permittivity had been observed as the frequency of the measurements will influence the polarization process. It is also known that in a typical resin system, the permittivity of epoxy is determined by the number of orientable dipoles within the system and their ability to orient under an applied electric field (Eloundou 2002, Zhang et al. 1996). The epoxy resin tends to have higher effective permittivity within a lower frequency range as most of the free dipolar functional groups within the epoxy chain are able to orientate under lower frequency of applied field. When the frequency of the applied voltage increases, it will become more difficult for larger dipolar groups to orientate themselves. Thus the effect of dipolar groups on the permittivity is reducing continuously as the frequency increases. Therefore the effective permittivity of net epoxy resin will decrease with increasing frequency in the measured frequency range. Similarly, the increasing frequency of the applied filed will also result in reduction of $\mathrm{SiO}_{2} / \mathrm{Al}_{2} \mathrm{O}_{3}$ fillers' inherent permittivity (Nelson and Fothergill 2004, Santos et al. 2002). According to the effective medium theories and mixing rules which are used to work out the permittivity within a polymer-particle heterogeneous system (Brosseau et al. 2001), the combination of both effects results in the reduction of epoxy/nanocomposites' permittivity with increasing frequency.

Another interesting observation from this study is the presence of inorganic nano fillers and their loading concentrations have strong influence to the effective permittivity of resulting composites. It can be seen from Fig. 6(a) that the epoxy/nanocomposites have lower permittivity compared with net epoxy resin in the measured frequency range. The effective permittivity of the epoxy- $\mathrm{SiO}_{2}$ nanocomposites with $0.1 \%$ nano filler loading is similar to the unfilled epoxy. It is also observed that the permittivity for epoxy- $\mathrm{SiO}_{2}$ nanocomposites decrease as the filler concentration increases, and the relative permittivity reaches its lowest value when the loading concentration is between $1 \%$ and $3 \%$. Then the permittivity of epoxy- $\mathrm{SiO}_{2}$ nanocomposites begins to increase as filler concentration increases further more. A similar observation for epoxy- $\mathrm{Al}_{2} \mathrm{O}_{3}$ nanocomposites has also shown in Fig. 6(b), but the lowest permittivity occurs between $0.5 \%$ and $1 \%$. Moreover, the epoxy- $\mathrm{Al}_{2} \mathrm{O}_{3}$ nanocomposite loading with $5 \mathrm{wt} \%$ nano particles has higher effective permittivity compared with net epoxy resin within the measured range. This observation is surprising as most of the earlier investigations showed that lower loading concentration (even much less than 1\%) of nano-size fillers will lead to lower permittivity (Singha and Thomas 2008a). Earlier study also stated that the permittivity of epoxy/nanocomposites increases with increasing nano filler concentration in epoxy (Singha and Thomas 2008a). However, there are also similar observations in the literature where the nanocomposites' permittivity drops at lower concentration and then increases again as the filler concentration increases to a high value (more than 0.5\%) (Shi et al. 2009). The changes of effective permittivity with the presence of the nano size filler and their loading concentration may be caused by the following reason: the influence of the filler's inherent permittivity on resulting nanocomposites' permittivity increase as the loading concentration increases. The permittivity of two phase dielectric satisfies the Lichtenecker-Rother mixing rule can be written as Eq. (4)

$$
\log \varepsilon_{c}=x \log \varepsilon_{1}+y \log \varepsilon_{2}
$$

where, $\varepsilon_{c}$ is the resultant composite permittivity, $\varepsilon_{1}$ and $\varepsilon_{2}$ are the permittivity of filler and epoxy 
and $x, y$ are the concentrations of filler and polymer. It is known that the nano size $\mathrm{SiO}_{2}$ and $\mathrm{Al}_{2} \mathrm{O}_{3}$ fillers have higher permittivity compared with the net epoxy resin. That could be one of the reasons leading to an increase of effective permittivity with higher loading concentrations. Since the presence of nano size fillers tend to enhance the effective permittivity of resulting composites, the decrease of permittivity in epoxy nanocomposites with lower loading concentration became another interesting observation. It is believed that a decreasing in permittivity of epoxy resin/ nanocomposites is only possible to occur when a reduction in electrical polarization has happened within the composites. The interfacial or space charge polarization, which is caused by the space charge accumulation near the interface between base resin system and nano size particles, will affect the effective permittivity of composites. As the interfacial polarization only occurs under lower frequency ranges (up to $10^{3} \mathrm{~Hz}$ ), this means that the presence of interfacial polarization normally leads to a clear variation of permittivity with respect to the measured frequency range. Thus the effect of interfacial polarization on the decrease of permittivity in epoxy nanocomposites with lower loading concentration could be neglected as the measured results in this investigation show that the reduction of effective permittivity with lower nano loading concentration is irrespective to the frequency. Another possibility is the reduction of mobility of the dipolar groups within the composites will reduce the polarization within the composites (Singha and Thomas 2008b). The interaction between nano size filler and epoxy chain reduces the mobility of epoxy chain in the bulk material, which will result in a decreasing of the effective permittivity of epoxy/nanocomposites. When a small amount of nano filler is loaded into epoxy, due to the interaction between filler and epoxy chain, the thin immobile nano layers can be formed. Those thin immobile nano layers will restrict the mobility of the epoxy chain (Tsagaropoulos and Eisenberg 1995). As the loading concentration increases, more immobile nano layer formed and the mobility of epoxy chain decreased continuously, resulting in reduction of nanocomposites' permittivity.

It can be obtained from the rule that the influence of filler permittivity on nanocomposites increases as the filler concentration increases. Thus epoxy- $\mathrm{SiO}_{2}$ nanocomposite has lower permittivity compared with unfilled epoxy at lower loading concentration. Further increasing on loading concentration of the filler will result in increasing of nanocomposites' permittivity. Fig. 6 (b) also gives similar observations. It also needs to be noticed that epoxy- $\mathrm{Al}_{2} \mathrm{O}_{3}$ nanocomposites have higher permittivity compared with nanocomposites with nano $\mathrm{SiO}_{2}$ fillers. This is because nano $\mathrm{Al}_{2} \mathrm{O}_{3}$ particles have a high permittivity than nano $\mathrm{SiO}_{2}$ particles. So the type of nano fillers also has a significant influence on nanocomposites' permittivity.

\subsection{Tan delta}

The variation of tan delta value in both epoxy- $\mathrm{SiO}_{2} / \mathrm{Al}_{2} \mathrm{O}_{3}$ composites are also presented in Fig. 7. The tan delta value in both epoxy- $\mathrm{SiO}_{2} / \mathrm{Al}_{2} \mathrm{O}_{3}$ nanocomposites decrease with the frequency within lower frequency ranges. The tan delta value for both epoxy- $\mathrm{SiO}_{2} / \mathrm{Al}_{2} \mathrm{O}_{3}$ composites reaches a minimum value around $100 \mathrm{~Hz}$ and then begin to increase with the frequency. It can also be observed from Fig. 7 that the tan delta value of unfilled epoxy is higher than epoxy- $\mathrm{SiO}_{2} / \mathrm{Al}_{2} \mathrm{O}_{3}$ nanocomposites under lower frequency range (less than $100 \mathrm{~Hz}$ ). When the frequency is higher than $100 \mathrm{~Hz}$, there is no significant difference in tan delta value between unfilled epoxy and both epoxy$\mathrm{SiO}_{2} / \mathrm{Al}_{2} \mathrm{O}_{3}$ nanocomposites. Therefore the presence of nano size particles seems to have a stronger influence in lower frequency range whereas the tan delta characteristic of net epoxy resin dominates the variation within a frequency range above $100 \mathrm{~Hz}$ in the measurement range. Such a reduction in 


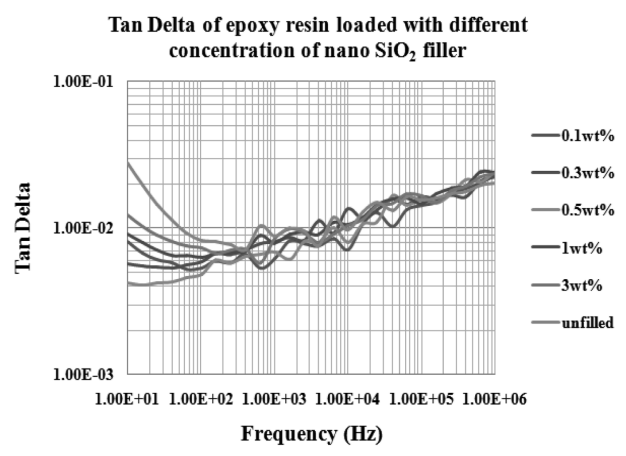

(a) Epoxy-SiO2 nanocomposites

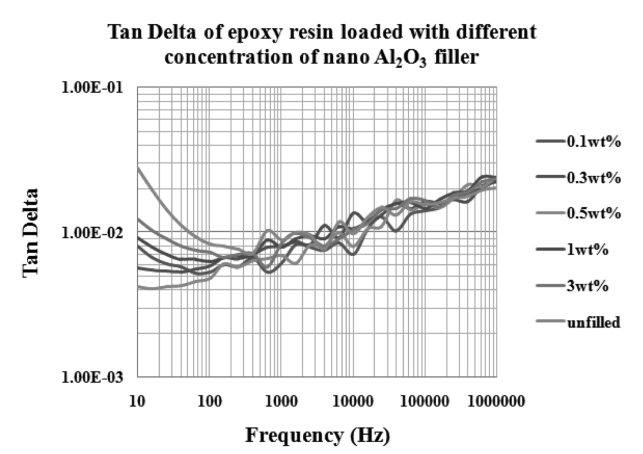

(b) Epoxy-A12O3 nanocomposites

Fig. 7 Variations of Tan Delta with respect to frequency

tan delta value, especially at a low frequency range, was also observed in other studies (Ciuprina et al. 2008, Singha and Thomas 2008b). As the electrical conductivity of epoxy composites contribution to its tan delta value, the variation of tan delta value in both net epoxy resin and epoxy nanocomposites in lower frequency range may result in the electrical conductivity of the nanocomposites having been affected by the presence of nano size fillers. As this study was carried out under constant temperature, the influence of the relaxation time of the charge carriers on the electrical conductivity of epoxy nanocomposites can be ignored. Thus the number of charge carriers and applied frequency become dominating factors of the electrical conductivity of epoxy nanocomposites. As discussed in section 3.1, the presence of nano size fillers inside epoxy will restrict the chain mobility and result in reducing electric conductivity as such restriction limited the generation of mobile charge and the movement of charge carriers in polymer dielectrics (Singha and Thomas 2008a,b), especially at a lower frequency range where the conductivity will play a more important role. Thus the variation of tan delta value at low frequency range may be due to the influence of inorganic fillers' electrical conductivity.

\subsection{Space charge}

The "volts-off" space charge accumulation of specimens with different nano $\mathrm{SiO}_{2}$ filler concentrations is shown in Fig. 8. It can be seen from Fig. 8(a), a large amount of homocharges is observed for unfilled epoxy, especially near the cathode side. As the duration of the applied voltage increases, the amount of charge in the specimen increases as well. The homocharge usually occurs when the injected charges are trapped in the interface between base epoxy and nano fillers under the applied field. Charges are dictated by homocharges, which means that the charge injection takes place from both electrodes (Fabiani et al. 2008). The heterocharges which is caused by ionization process may also present in the specimen. However, as the PEA system only measures the net charges, it might be covered by the charge injection. Compared with the unfilled samples, Fig. 8(b) shows a similar charge distribution in specimen with $1 \%$ nano $\mathrm{SiO}_{2}$ filler. However, it is noticed that $1 \%$ nanocomposite has a slower initial charge build-up rate. The magnitude of charges in $1 \%$ samples is slightly less than that in the unfilled one. The reason for such decreasing in the magnitude of space charge is either the presence of nano filler has hindered the charge injection or more heterocharges are generated due to the ionization process. According to the multi core model 


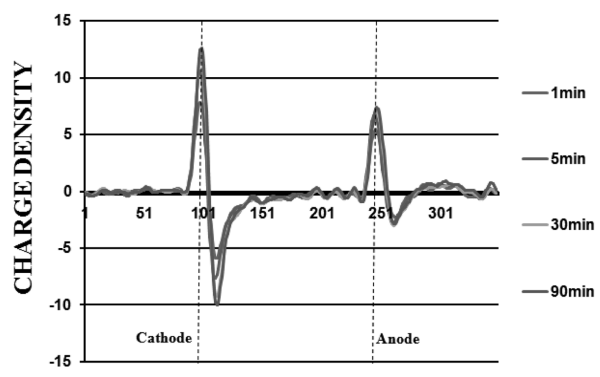

(a) unfilled

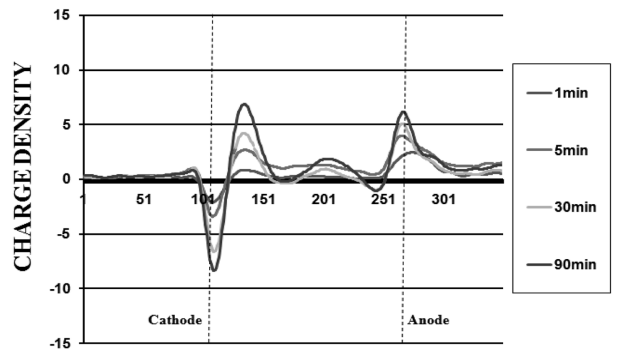

(c) $3 \mathrm{wt} \%$

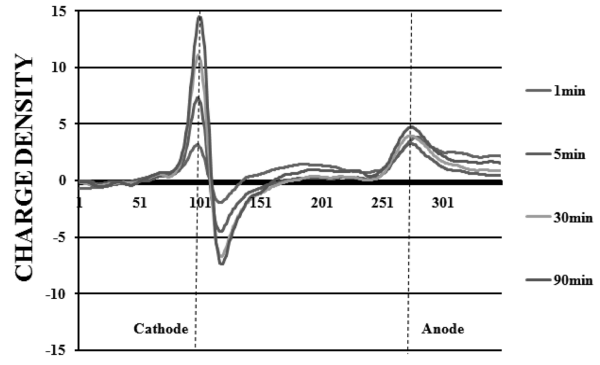

(b) $1 \mathrm{wt} \%$

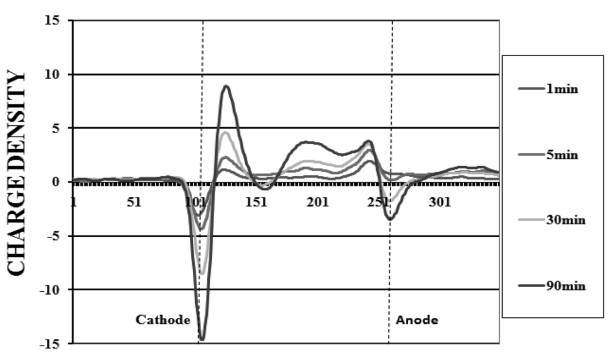

(d) $5 \mathrm{wt} \%$

Fig. 8 Charge build-up in epoxy- $\mathrm{SiO}_{2}$ nanocomposites at $6 \mathrm{KV}$

of nanocomposites which is present by Tanaka (2005), when the nano particles were introduced into the base epoxy resin, a shallow trap band is created (Montanari et al. 2004), which either distribute or replace the original trap band, especially at higher loading concentrations. The presence of shallow trap band results in higher mobility of charge carriers, and hence causes less space charge accumulation. So lower charge injection rate should be observed in epoxy nanocomposites. However, the observation from Figs. 8(c) and 8(d) seems to disagree with such conclusions. On the other hand, as the presence of the nano $\mathrm{SiO}_{2}$ fillers, the heterocharges generated by ionization process should increase. Thus more heterocharges accumulated close to the electrodes. The small amount of heterocharges will cancel out with some of the injected charges. Therefore the net charges observation from the PEA system shows a small decrease in the magnitude of space charges. As shown in Fig. 8(c), when the filler concentration increases to 3\%, space charge distribution is very different. There is a positive peak close to the cathode as a result of heterocharges accumulation. A small amount of heterocharges is also observed adjacent to the anode. There are also some positive charges and a small amount of negative charges accumulated in the middle of the sample bulk. The presence of heterocharge accumulation adjacent to both electrodes is believed to be due to the increasing concentration of nano filler which results in more heterocharges formation. The two charge peaks within the middle of the sample are believed to be due to the charge injection from two electrodes respectively. It seems that the addition of nano size silicon fillers enhanced charge injections. Similar results were also observed for both epoxy and LLDPE samples loaded with higher concentration of nano fillers (Fothergill et al. 2004, Chen et al. 2007). When more fillers are added into the epoxy sample, more heterocharges are accumulated adjacent to the cathode and the charge peaks inside the middle of sample become more clear, as shown in Fig. 8(d). 


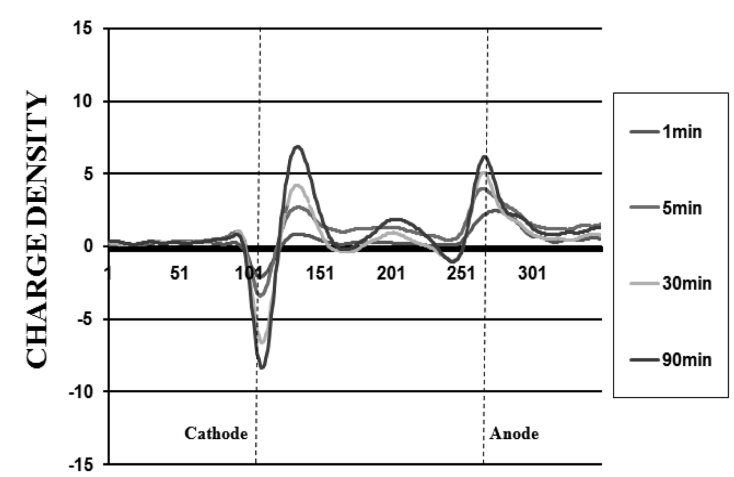

(a) $\mathrm{SiO}_{2}$

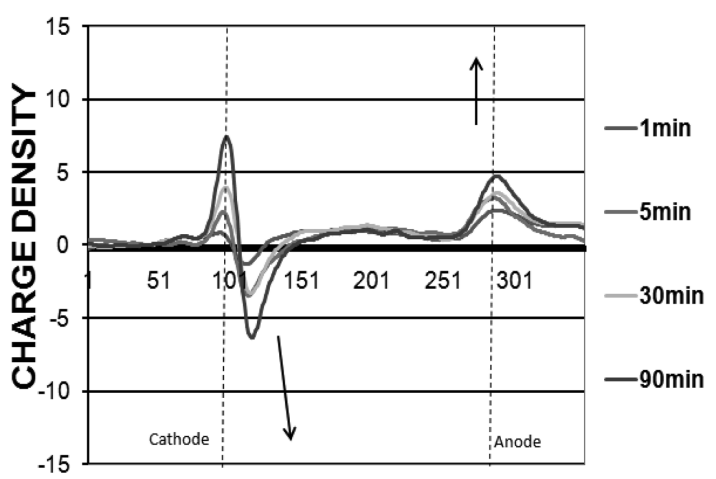

(b) $\mathrm{Al}_{2} \mathrm{O}_{3}$

Fig. 9 Charge build-up in $3 \mathrm{wt} \%$ epoxy- $\mathrm{SiO}_{2} / \mathrm{Al}_{2} \mathrm{O}_{3}$ nanocomposites at $6 \mathrm{kV}$

Fig. 9 shows the observation of space charge accumulation in both epoxy- $\mathrm{SiO}_{2} / \mathrm{Al}_{2} \mathrm{O}_{3}$ nanocomposites with $3 \%$ filler concentrations. It can be seen clearly that charges are dictated by homocharges in epoxy- $\mathrm{Al}_{2} \mathrm{O}_{3}$ nanocomposites, whereas in epoxy- $\mathrm{SiO}_{2}$ composites, charges are dominated by heterocharges. But there is a small amount of positive charge present in the middle of both samples. Generally speaking, the space charge built-up of epoxy resin loaded with $3 \mathrm{wt} \%$ nano $\mathrm{Al}_{2} \mathrm{O}_{3}$ fillers is similar to epoxy resin loaded with $1 \mathrm{wt} \%$ nano $\mathrm{SiO}_{2} /$ filler. The difference in charge formation between two nanocomposites is believed to be caused by the amount of heterocharges accumulated adjacent to the electrodes. Thus compared with $\mathrm{Al}_{2} \mathrm{O}_{3}$ particles, the same amount of $\mathrm{SiO}_{2}$ particles seems to have a better enhancement on the ionization process in nanocomposites. The reason for such a difference observation may be due to the higher permittivity of nano $\mathrm{Al}_{2} \mathrm{O}_{3}$ fillers. The difference in particle size, may also become one of the reasons.

\subsection{Breakdowns}

The Weibull distribution plots for both epoxy resin nanocomposites filled with $20 \mathrm{~nm}$ and $80 \mathrm{~nm}$ nano $\mathrm{SiO} 2$ fillers, are shown in Fig. 10. In addition, pure epoxy resin and micro filled epoxy resin composites samples were also tested and the test results were compared with those obtained from epoxy resin nanocomposites. The maximum likelihood estimation (MLE) was used as the parameter estimator for the breakdown data, thus producing the Weibull parameters shown in Table 1. For epoxy nanocomposites with $\mathrm{SiO} 2$ fillers, lower breakdown strengths were observed. It can be seen from the $20 \mathrm{~nm}$ plot that, compared with both pure and micro filled epoxy resin, for all epoxy resin nanocomposites, there is a reduction in breakdown strength. As shown in Fig. 10, the $1 \%$ micro filled sample shows a marginally lower breakdown strength $(\eta)$ and slightly higher scatter $(\beta)$ compared to the pure sample. The epoxy resin nanocomposites specimens, on the other hand, showed a clear reduction in the breakdown strength of at least $10 \mathrm{kV} / \mathrm{mm}$, with $5.0 \%$ nano filled specimens showing the worst characteristics, being $16.2 \mathrm{kV} / \mathrm{mm}$ lower than pure epoxy resin samples, at $124.1 \mathrm{kV} / \mathrm{mm}$.

In summary, the presence of nano size fillers shows no improvement in dielectric breakdown behavior of epoxy resin composites. Similar results were also observed by Imai et al. (2006), Singha and Thomas (2008a). Singha et al. observed a relatively significant reduction in breakdown 


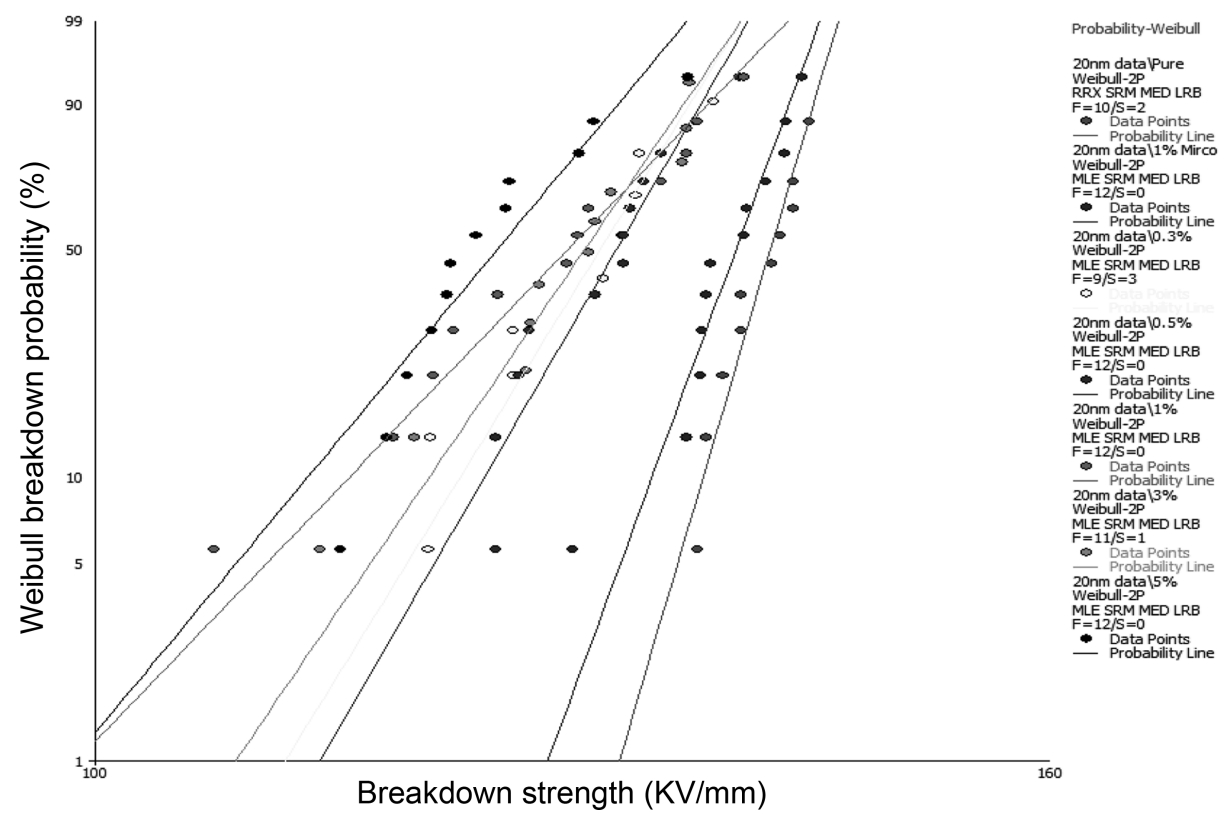

Fig. 10 Influence of $\mathrm{Nano} \mathrm{SiO}_{2}$ loading levels in epoxy resin on breakdown strength pure and micro-filled epoxy resin

Table 1 Table of Weibull parameters from MLE for epoxy- $\mathrm{SiO}_{2} / \mathrm{Al}_{2} \mathrm{O}_{3}$ nanocomposites relative to pure and micro-filled epoxy resin

\begin{tabular}{ccc}
\hline \hline Sample & Scale parameter $(\eta)(\mathrm{kV} / \mathrm{mm})$ & Shape parameter $(\beta)$ \\
\hline Pure & 140.3 & 56.7 \\
\hline $1 \%$ micro & 138.2 & 45.7 \\
\hline $0.3 \%$ nano & 129.9 & 27.3 \\
\hline $0.5 \%$ nano & 130.9 & 29.0 \\
\hline $1.0 \%$ nano & 128.9 & 17.5 \\
\hline $3.0 \%$ nano & 129.1 & 24.6 \\
\hline $5.0 \%$ nano & 124.1 & 20.2 \\
\hline
\end{tabular}

strength when a range of loading levels of epoxy-TiO2 and epoxy- $\mathrm{Al}_{2} \mathrm{O}_{3}$ composites were ramp tested. The addition of nano-particles to epoxy resin does however significantly reduce the shape parameter $(\beta)$, a result which is contrary to several other studies, including Singha et al. and Hu et al. (Tanaka 2005). Such reduction in dielectric breakdown strength is due to the presence of nano size filler within base epoxy resin which act as defects and therefore results in electric field enhancement (Nelson and Hu 2005, Roy et al. 2007). Many other papers report that the addition of inorganic nano size fillers will enhance the dielectric breakdown strength of base resin. Such a difference may be due to the dispersion rate of nano fillers within the base resin materials, as lower dispersion rates of the nano fillers will lead to larger field enhancement. Thus the epoxy nanocomposites without surface treatment used in this study shows slight reduction on the dielectric breakdown strength whereas the 
surface treated nanocomposites have higher breakdown strength compared with net epoxy resin.

From the space charge measurement results, with nano filler loading, the net charges observation from the PEA system shows a small decrease in the magnitude of space charges. However, it needs to be noticed that the results are from "volts-off" measurements, which measures charge formation immediately after the applied voltage has been removed. Therefore due to the delay between removal of the applied voltage and readings, only space charges captured by deeper traps were measured. Deep trap level means that the space charge is less possible to escapes from the trap. Therefore the deep trap does not help to develop material breakdown. From the space charge measurement results, it can be seen that the presence of nano fillers shows a reduction on the deep charge accumulation. However, when space charge escapes from deep traps, there will be more energy released. According to the current results, it is hard to see whether the presence of nano filler have any negative effect on breakdown behavior of epoxy resin. Moreover, the fast trapped space charges that escaped before the "volts-off" measurements should also be considered.

\section{Conclusions}

Both the dielectric permittivity and space charge accumulation in epoxy nanocomposites loaded with different concentration of nano size $\mathrm{SiO}_{2}$ and $\mathrm{Al}_{2} \mathrm{O}_{3}$ fillers have been investigated using dielectric spectroscopy and the PEA method. The following conclusion may be drawn based on this study. The permittivity for both epoxy- $\mathrm{SiO}_{2} / \mathrm{Al}_{2} \mathrm{O}_{3}$ nanocomposites decreases at lower concentration (less than 1\%). The relative permittivity of nanocomposites appears to have a minimum value with a threshold filler concentration $\left(1 \mathrm{wt} \%\right.$ for nano $\mathrm{SiO}_{2}$ and $0.5 \mathrm{wt} \%$ for nano $\mathrm{Al}_{2} \mathrm{O}_{3}$ ). When the filler content is above the threshold value, the permittivity of nanocomposites begins to increase with filler concentration. Such increase is believed to be due to the higher permittivity of inorganic nano fillers. Thus as expect, the epoxy- $\mathrm{Al}_{2} \mathrm{O}_{3}$ nanocomposite has a higher permittivity than epoxy- $\mathrm{SiO}_{2}$ nanocomposites as the $\mathrm{Al}_{2} \mathrm{O}_{3}$ particles have a higher inherent permittivity. The reduction of permittivity at lower loading concentration is the result of restriction of the mobility of dipole groups within the nanocomposites due to the interaction between epoxy and nano size fillers. Less space charge accumulation had been observed within the epoxy/nanocomposites compare with net epoxy sample. Such a reduction in magnitude of space charge charges is believed to be due to the presence of nano particles that seem to enhance the ionization process inside the sample, especially at higher filler concentrations. It can also be observed that a higher content of nano size filler $\left(5 \mathrm{wt} \%\right.$ for $\left.\mathrm{SiO}_{2}\right)$ will lead to more complicated charge accumulation, which is due to the combination of charge injection from electrode and enhancement of ionization process inside the nanocomposites. The filler type also shows a significant influence on space charge accumulations, which may be due to the difference in permittivity, filler size and the interaction with epoxy resin. The presence of nano size fillers shows a reduction in the breakdown strength of epoxy resin composites. Moreover, there is a significant reduction in the shape parameter $(\beta)$ as well. This unexpected result can be attributed to a number of factors. The space charge accumulation also has a complicated influence on the dielectric breakdown behaviors of epoxy resin. In summary, as the presence of huge polymerfiller interface inside the nanocomposites, the addition of inorganic nano size fillers seem to have a strong influence on the dielectric properties of epoxy/nanocomposites. 


\section{References}

Brosseau, C., Queffelec, P. and Talbot, P. (2001), "Microwave characterization offilled polymers", J. Appl. Phys., 89, 4532-4540.

Castellon, J., Agnel, S., Toureille, A., Freìchette, M.F., Savoie, S., Krivda, A. and Schmidt, L.E. (2010), "Space charge behaviour on epoxy based dielectrics filled with micro and nano silica", Proceedings of the 10th IEEE International Conference on Solid Dielectrics (ICSD), Potsdam, July.

Castellon, J., Agnel, S., Toureille, A. and Frechette, M. (2008), "Space charge characterization of multi-stressed microcomposite nano-filled epoxy for electrotechnical applications", Annual Report Conference on Electrical Insulation and Dielectric Phenomena (CEIDP), Quebec, October.

Ciuprina, F., Plesa, I., Notingher, P.V., Tudorache, T. and Panaitescu, D. (2008), "Dielectric properties of nanodielectrics with inorganic fillers", Annual Report Conference on Electrical Insulation and Dielectric Phenomena (CEIDP), Quebec, October.

Dissado, L.A. Mazzanti, G. and Montanari, G.C. (1997), "The role of trapped space charges in the electrical aging of insulating materials", IEEE T. Dielect. El. In., 4(5), 496-506.

Dissado, L.A., and Fothergill, J.C. (1992), Electrical degradation and breakdown in polymers, Peter Peregrinus Ltd., IEEE Mat. Dev. Serv., London.

Eloundou, J.P. (2002), "Dipolar relaxations in an epoxy-amine system”, Eur. Polym. J., 38(3), 431-438.

Fabiani, D., Montanari, G.C., Dardano, A., Guastavino, G., Testa, L. and Sangermano, M. (2008), "Space charge dynamics in nanostructured epoxy resin", Annual Report Conference on Electrical Insulation and Dielectric Phenomena (CEIDP), Quebec, October.

Fothergill, J.C., Nelson, J.K. and Fu, M. (2004), "Dielectric properties of epoxy nanocomposites containing $\mathrm{TiO}_{2}$, $\mathrm{Al}_{2} \mathrm{O}_{3}$ and $\mathrm{ZnO}$ fillers", Annual Report Conference on Electrical Insulation and Dielectric Phenomena (CEIDP), Boulder, CO, October.

Chen, G., Zhang, C. and Stevens, G. (2007), "Space charge in LLDPE loaded with nanoparticles", Annual Report Conference on Electrical Insulation and Dielectric Phenomena (CEIDP), Vancouver, October.

Green, C.D. (2008), "Polyethylene-montmorillonite nanocomposites", Doctoral Thesis, University of Southampton.

Hajiyiannis, A., Chen, G., Zhang, C. and Stevens, G. (2008), "Space charge formation in epoxy resin including various nanofillers", Annual Report Conference on Electrical Insulation and Dielectric Phenomena (CEIDP), Quebec, October.

Imai, T., Sawa, F., Ozaki, T., Inoue, Y., Shimizu, T. and Tanaka, T. (2006), "Comparison of insulation breakdown properties of epoxy nanocomposites under homogeneous and divergent electric fields", Proceedings of the IEEE Conference on Electronic Insulation and Dielectric Phenomena (CEIDP), Kansas City, October.

Lewis, T.J. (2004), "Interfaces and nanodielectrics are synonymous", Proceedings of the 2004 IEEE International Conference on Solid Dielectrics, Toulouse, July.

Montanari, G.C., Faviani, D., Palmieri, F., Kaempfer, D., Thomann, R. and Mülhaupt, R. (2004), "Modification of electrical propertiesand performance of EVA and PP insulation throughnanostructure by organophilic silicates", IEEE T. Dielect. El. In., 11(5), 754-762.

Nelson, J.K. and Hu, Y. (2004), "The impact of nanocomposite formulations on electrical voltage endurance", Proceedings of the 2004 IEEE International Conference on Solid Dielectrics, Toulouse, July.

Nelson, J.K. and Hu, Y. (2005), "Nanocomposite dielectrics - properties and implications", J. Phys. D: Appl. Phys., 38(2), 213-222.

Nelson, J.K. and Fothergill, J.C. (2004), "Internal charge behavior of nanocomposites", Nanotechnology, 15(5), 586-595.

Roy, M., Nelson, J.K., MacCrone, R.K. and Schadler, L.S. (2007), "Candidate mechanisms controlling the electrical characteristics of silica/XLPE nanodielectrics”, J. Mater. Sci., 42(11), 3789-3799.

Santos, J. de los, Garcia, D. and Eiras, J.A. (2002), "Dielectric characterization ofmaterials at microwave frequency range", Mat. Res., 6(1), 97-101.

Shi, H., Gao, N., Jin, H., Zhang, G. and Peng, Z. (2009), "Investigation of the effects of nano-filler on dielectric properties of epoxy based composites", Proceedings of the IEEE 9th International Conference on the Properties and Applications of Dielectric Materials, Harbin, July.

Singha, S. and Thomas, M.J. (2008a), "Dielectric properties of epoxy nanocomposites", IEEE T. Dielect. El. In., 
15, 12-23.

Singha, S. and Thomas, M.J. (2008b), "Permittivity and tan delta characteristics of epoxy nanocomposites in the frequency range of $1 \mathrm{MHz}-1 \mathrm{GHz}$ ", IEEE T. Dielect. El. In., 15(1), 2-11.

Singha, S. and Thomas, M.J. (2008c), "Reduction of permittivity in epoxy nanocomposites at low nano-filler loadings", Annual Report Conference on Electrical Insulation and Dielectric Phenomena, Quebec, October.

Tanaka, T. (2005), "Dielectric nanocomposites with insulating properties", IEEE T. Dielect. El. In., 12(5), 914928.

Tsagaropoulos G. and Eisenberg, A. (1995), "Dynamic mechanical study of the factors affecting the two glass transition behavior of filled polymers similarities and differences with random ionomers", Macromolecules, 28(18), 6067-6077.

Zheng, F., Zhang, Y., Gong, B., Chen, L., Xu, J. and Wang, C. (2005), "Characteris- tics of space charge in PMM $\backslash 4$ A after electron beam radiation", Chinese J. Mat. Res., 19(4), 431-436.

Zhang, L.D., Zhang, H.F., Wang, G.Z., Mo, C.M. and Zhang, Y. (1996), "Dielectric behavior of nano-TiO2 bulks", Phys. Stat. Sol., 157(2), 483-491. 